\title{
Simulating consequences of choosing a breeding goal for organic dairy production
}

\author{
M. Slagboom, ${ }^{* 1}$ A. Wallenbeck, $†$ L. Hjortø, ${ }^{*}$ A. C. Sørensen, ${ }^{*}$ L. Rydhmer, $†$ J. R. Thomasen, ${ }^{*} \ddagger$ and M. Kargo*§ \\ *Department of Molecular Biology and Genetics, Center for Quantitative Genetics and Genomics, Aarhus University, 8830 Tjele, Denmark \\ †Department of Animal Breeding and Genetics, Swedish University of Agricultural Sciences, 75651 Uppsala, Sweden \\ ¥VikingGenetics, 8960 Assentoft, Denmark \\ §SEGES Cattle, 8200 Aarhus N, Denmark
}

\begin{abstract}
In Denmark, Finland, and Sweden, the Nordic Total Merit index is used as the breeding selection tool for both organic and conventional dairy farmers based on common economic models for conventional dairy farming. Organic farming is based on the principles of organic agriculture (POA) defined by the International Federation of Organic Agriculture Movements. These principles are not set up with an economic point of view, and therefore it may be questionable to use a breeding goal (BG) for organic dairy production based on economic models. In addition to economics and the principles of organic agriculture, it is important to look at farmers' preferences for improving BG traits when setting up a BG for organic farming. The aim of this research was to set up, simulate, and compare long-term effects of different BG for organic and conventional dairy production systems based on economic models, farmers' preferences, and POA, with particular emphasis on disease resistance or on roughage consumption and feed efficiency. The BG based on economic models and on farmers' preferences were taken from previous studies. The other BG were desired gains indices, set up by means of a questionnaire about relatedness between the POA and BG traits. Each BG was simulated in the stochastic simulation program ADAM. The BG based on POA, with particular emphasis on disease resistance or on roughage consumption and feed efficiency, caused favorable genetic gain in all 12 traits included in this study compared with 6 traits for the other BG. The BG based on POA, with particular emphasis on disease resistance or on roughage consumption and feed efficiency, were very different from BG for organic and conventional production based on economic models and farmers' preferences in both simulated genetic change
\end{abstract}

Received December 19, 2017.

Accepted August 24, 2018.

${ }^{1}$ Corresponding author: margotslagboom@mbg.au.dk and correlations between BG. The BG that was created based on the principles of organic agriculture could be used as a specific index for organic dairy farming in Denmark, but this index was economically not very sustainable. Hence, an intermediate breeding goal could be developed by breeding companies to address both economics and the principles of organic agriculture.

Key words: organic farming, breeding goal, dairy cow, desired gains index

\section{INTRODUCTION}

In Denmark, Finland, and Sweden, the same breeding goal (BG) is used for organic and conventional dairy production. The Nordic Total Merit Index (NTM) is used as the breeding selection tool for both production systems. As with many other dairy cow total merit indices, the NTM includes functionality and health in addition to production traits. Relative emphasis on production and other traits differs between countries (Miglior et al., 2005), and relative emphasis on different traits might also differ for different production systems, such as organic and conventional dairy production.

Some of the major differences between organic and conventional dairy production are feeding strategy, outdoor access, and use of antibiotics. In organic dairy production in Europe, all feed must be organic, at least $50 \%$ of the feed must be produced by the farm itself, at least $60 \%$ of the ration must be roughage, and cows must have pasture access in the grazing season (The Council of the European Union, 2008). In addition, the rules for using veterinary medicine are stricter and the withdrawal period after treatment is twice as long as for conventional dairy production (The Council of the European Union, 2008). Regulations for organic farming are based on the principles of organic agriculture (POA) defined by the International Federation of Organic Agriculture Movements (IFOAM), namely the principles of health, ecology, fairness, and care (IFOAM, 2016). These POA state that organic production should enhance the health of all living beings, be based 
on living ecological systems and cycles, ensure fairness at all levels of the food chain, and protect the well-being of current and future generations and the environment. However, the POA are not set from an economic point of view and, therefore, it may be questionable to use a $\mathrm{BG}$ for organic dairy production based solely on economic models. A BG based on the POA can be set up by interpreting and translating the POA into breeding goals for animal production; however, animals are only mentioned a few times in IFOAM's POA, and genetics is mentioned even less.

An alternative base for a specific BG for organic production is farmers' preferences for improving BG traits, which can be measured with a preference survey. A Swedish survey showed that organic dairy farmers prefer disease resistance more and milk production less than conventional dairy farmers (Ahlman et al., 2014). The opposite was seen in a Danish study, with organic farmers preferring improvements in milk production more than conventional farmers (Slagboom et al., 2016a,b). Other traits might have to be added to a BG for organic dairy production in Denmark; for instance, including roughage consumption considering the organic regulations on pasture access and amount of roughage in the ration. When the importance of traits differs between organic and conventional dairy production, it might be advantageous to create different BG for each of these production systems. Only 1 breeding line with 1 BG is used in Danish dairy production, and the effect of having a specific BG for organic dairy production needs to be quantified. The aim of the current research was to set up, simulate, and compare long-term effects of different $\mathrm{BG}$ for organic and conventional dairy production systems based on economic models, farmers' preferences, and POA, with particular emphasis on disease resistance or on roughage consumption and feed efficiency.

\section{MATERIALS AND METHODS}

\section{Genetic Parameters}

Twelve traits were included in simulation of the different BG (Table 1). These traits were chosen because they are of economic importance or were expected to be of particular importance to an organic BG based on POA, such as roughage consumption. The current NTM includes most of these traits, although sometimes defined differently (e.g., fertility is not measured as pregnancy rate, but the fertility index includes number of inseminations and days from first to last insemination among others; Nordic Cattle Genetic Evaluation, 2017). For milk production, we chose the trait ECM because it includes milk, fat, and protein production. This trait was also chosen because it was used for a farmer preference survey in which the number of traits that we wanted to include was limited; thus, including 1 trait made more sense than including milk, protein, and fat production separately (as in the NTM). Feed efficiency and roughage consumption are not included in the current NTM.

Heritability and genetic variance for the traits were based on estimates used in Interbull evaluations for Holstein cattle (Interbull, 2008, 2010, 2012, 2015) and estimates found in the literature (Van Arendonk et al., 1991; Hansen et al., 2002; Weller and Ezra, 2008; Laursen et al., 2009; Fuerst-Waltl and Sørensen, 2010; Vallimont et al., 2011; Heise et al., 2016; Li et al., 2016; Table 2). Heritability values were rounded to 2 decimal places. Genetic and phenotypic correlation matrices were constructed using relevant reports in the scientific literature (Table 2). Residual correlations were calculated from genetic and phenotypic correlations, where estimates from Danish studies or similar conditions for Holstein cows were preferred. Reliable

Table 1. Description of traits included in the simulation in this study

\begin{tabular}{lll}
\hline Trait & Abbreviation & Description \\
\hline Cow fertility & CoF & Pregnancy rate in cows, \% \\
Heifer fertility & HeF & Pregnancy rate in heifers, \% \\
Calving difficulty & CD & Incidence of a difficult calving per lactation as a binary trait \\
Calf mortality & CaM & Death within 15 mo after birth as a binary trait \\
Cow mortality & CoM & Mortality and involuntary culling per lactation as a binary trait \\
Hoof and leg diseases & HLD & Incidence of hoof and leg diseases per lactation as a binary trait \\
Mastitis & OD & Incidence of clinical mastitis per lactation as a binary trait \\
Other diseases & bD & binary trait \\
Milk production & MP & ECM ${ }^{1}$ production per milking day \\
Beef production & BP & Growth of bul and heifer calves in $\mathrm{kg} /$ year \\
Feed efficiency & FE & ECM production per feed unit \\
Roughage consumption & RC & Dry matter intake in $\mathrm{kg} / \mathrm{d}$ \\
\hline
\end{tabular}

${ }^{1}$ Test-day production of ECM $(\mathrm{kg})$ was calculated as $[\mathrm{kg}$ of milk $\times(383 \times$ fat $\%+242 \times$ protein $\%+780.8)] / 3,140$. 
Table 2. Genetic and phenotypic parameters used in the simulation ${ }^{1}$ [heritabilities are on the diagonal, genetic correlations above the diagonal, and phenotypic correlations below the diagonal $]^{2}$

\begin{tabular}{|c|c|c|c|c|c|c|c|c|c|c|c|c|c|}
\hline Trait $^{3}$ & $\mathrm{CoF}$ & $\mathrm{HeF}$ & $\mathrm{CD}$ & $\mathrm{CaM}$ & $\mathrm{CoM}$ & HLD & MA & OD & $\mathrm{MP}$ & $\mathrm{BP}$ & $\mathrm{FE}$ & $\mathrm{RC}$ & $\sigma_{\mathrm{a}}^{4}$ \\
\hline $\mathrm{HeF}$ & 0.05 & 0.01 & 0.00 & -0.05 & 0.15 & -0.05 & -0.25 & -0.25 & -0.30 & -0.05 & -0.10 & 0.25 & 4.16 \\
\hline CD & 0.35 & 0.00 & 0.06 & 0.05 & -0.40 & 0.00 & 0.00 & 0.10 & 0.25 & 0.10 & 0.15 & 0.05 & 0.21 \\
\hline CoM & 0.00 & 0.00 & 0.00 & 0.15 & 0.07 & 0.40 & 0.35 & 0.40 & -0.30 & 0.15 & -0.20 & -0.50 & 0.05 \\
\hline HLD & 0.00 & 0.00 & 0.00 & 0.15 & 0.40 & 0.01 & 0.45 & 0.20 & 0.25 & 0.00 & 0.15 & 0.05 & 0.03 \\
\hline MA & 0.00 & 0.00 & 0.25 & 0.05 & 0.15 & 0.00 & 0.07 & 0.15 & 0.35 & 0.15 & 0.20 & 0.05 & 0.08 \\
\hline $\mathrm{FE}$ & -0.15 & -0.10 & 0.00 & 0.00 & -0.20 & 0.15 & 0.20 & 0.05 & 0.60 & -0.25 & 0.14 & 0.10 & 0.08 \\
\hline $\mathrm{RC}$ & 0.00 & 0.00 & 0.05 & -0.05 & -0.05 & 0.05 & 0.05 & 0.05 & 0.30 & 0.05 & -0.30 & 0.46 & 1.20 \\
\hline
\end{tabular}

${ }^{1}$ This matrix was adjusted to be positive-definite before being used in the simulation.

${ }^{2}$ References: Bijma et al. (1998), Buch and Norberg (2008), Pedersen et al. (2015), Dematawewa and Berger (1998), Eaglen et al. (2013), FuerstWaltl and Sørensen (2010), Hansen et al. (2002), Heise et al. (2016), Interbull (2008, 2010, 2012, 2015), Kadarmideen et al. (2000), Laursen et al. (2009), Li et al. (2016), Oltenacu et al. (1991), Spurlock et al. (2012), Søndergaard et al. (2002), Sørensen (1999), Team Avlsværdivurdering (2014, 2015), Van Arendonk et al. (1991), Vallimont et al. (2011, 2013), VanRaden et al. (2004), Weller and Ezra (2008).

${ }^{3}$ Traits: cow fertility $(\mathrm{CoF})$, heifer fertility $(\mathrm{HeF})$, calving difficulty $(\mathrm{CD})$, calf mortality $(\mathrm{CaM})$, cow mortality (CoM), hoof and leg diseases (HLD), mastitis (MA), other diseases (OD), milk production (MP), beef production (BP), feed efficiency (FE), and roughage consumption (RC).

${ }^{4}$ Genetic standard deviations are in the unit of the traits described in Table 1.

correlations could not be found in the literature for all traits; therefore, some correlations were estimated using correlations between other traits in combination with expert opinion and biological reasoning. For example, missing genetic correlations for feed efficiency were based on genetic correlations for milk production multiplied by the genetic correlation between feed efficiency and milk production. A similar method was used for missing genetic correlations for heifer fertility and roughage consumption. Missing genetic correlations between roughage consumption and disease traits were set to 0.05 after discussions in our project group. In cases where phenotypic correlations were not available in the scientific literature, phenotypic correlations were assumed to be the same as genetic correlations. All correlations were rounded to the nearest 0.05 points. The same genetic parameters were used for all BG.

\section{Breeding Goals}

The following BG were developed and simulated (Table 3):

1. Conventional BG based on economic models (BGConvEc);

2. Organic BG based on economic models (BGOrgEc);

3. Organic BG based on a survey of farmers' preference (BGFarmPref);

4. Organic BG based on the principles of organic agriculture (BGOrgPrin);
5. Organic BG with particular emphasis on resistance to mastitis, hoof and leg diseases, and other diseases (BGDis); and

6. Organic BG with particular emphasis on roughage consumption and feed efficiency (BGFeed).

Breeding goals BGConvEc and BGOrgEc were derived from economic models in SimHerd for a typical conventional (BGConvEc) and organic (BGOrgEc) Danish dairy farm (Kargo et al., 2015). SimHerd is a tool used to help farmers make management decisions in dairy herds, which was altered to derive economic values. For BGFarmPref, a survey was carried out to study the preferences of organic farmers for BG traits. A description of the survey can be found in Slagboom et al. (2016a). The input for the survey was based on the $\mathrm{BG}$, using economic models for an organic dairy farm (BGOrgEc); the economic values of BGOrgEc were used to calculate improvements in trait units worth 100 $\operatorname{DKr}(\approx \$ 16)$ per trait, which were presented to farmers in the survey. Preferences of farmers were calculated in ranks, but also in the unit of the economic value of each trait. The BG weights in BGFarmPref consisted of preferences of organic farmers in the unit of the economic value added to the economic value of each trait in BGOrgEc. Economic values for BGConvEc, BGOrgEc, and BGFarmPref were multiplied by the genetic standard deviation (Table 2) to get the value per genetic standard deviation unit for each trait, which were used as BG weights (Table 3). Economic values were not derived for beef production and roughage consumption, 
Table 3. Breeding goal weights ${ }^{1}$ in Danish Krone $(1 \mathrm{DKr} \approx \$ 0.16)$ per genetic standard deviation unit for goal traits in the 6 different breeding goals, and accuracy of direct genomic values (DGV)

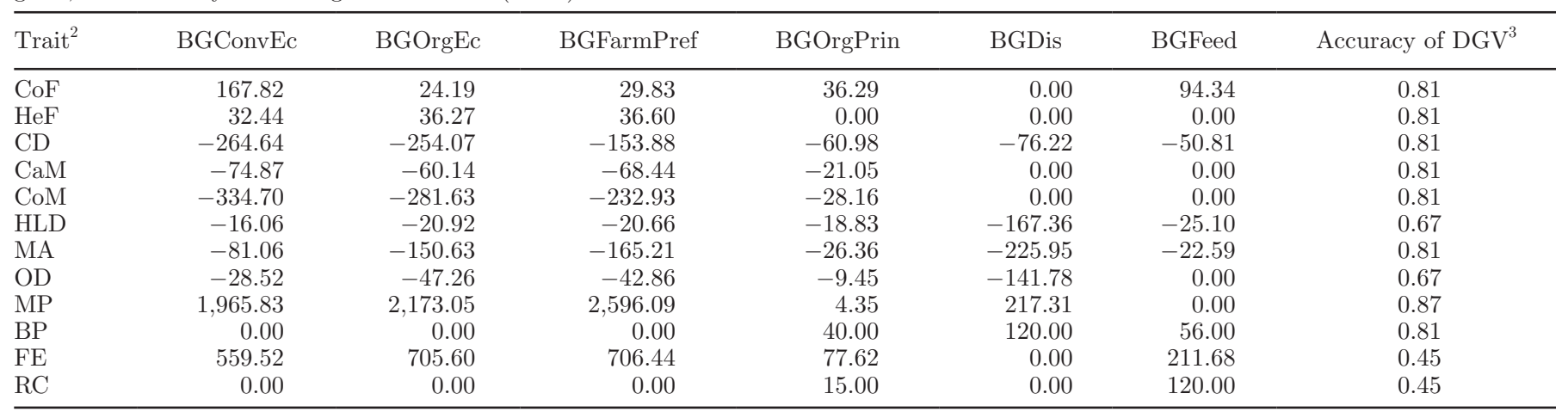

${ }^{1}$ Breeding goals: BGConvEc $=$ conventional based on economic models; BGOrgEc $=$ organic based on economic models; BGFarmPref $=$ organic based on farmers' preferences; BGOrgPrin = organic based on principles of organic agriculture; BGDis = organic with extra emphasis on disease resistance; $\mathrm{BGFeed}=$ organic with extra emphasis on roughage consumption and feed efficiency.

${ }^{2}$ Traits: cow fertility $(\mathrm{CoF})$, heifer fertility $(\mathrm{HeF})$, calving difficulty $(\mathrm{CD})$, calf mortality $(\mathrm{CaM})$, cow mortality (CoM), hoof and leg diseases (HLD), mastitis (MA), other diseases (OD), milk production (MP), beef production (BP), feed efficiency (FE), and roughage consumption (RC). ${ }^{3}$ DGV accuracies are based on genomic EBV reliabilities on average from young bulls born in 2014 (L. P. Sørensen, SEGES Cattle, Aarhus, Denmark, personal communication, September 8, 2016).

and thus these traits had a BG weight of 0 in the first 3 BG. The last 3 BG were set up with a desired gains approach.

The correlation between BG were calculated with the equation used in Buch et al. (2009):

$$
r_{1,2}=\frac{\mathbf{b}_{1}{ }^{\prime} \mathbf{G} \mathbf{b}_{2}}{\sqrt{\mathbf{b}_{1}{ }^{\prime} \mathbf{G} \mathbf{b}_{1} \mathbf{b}_{2}{ }^{\prime} \mathbf{G} \mathbf{b}_{2}}}
$$

where $r_{1,2}=$ the correlation between $2 \mathrm{BG}$; vector $\mathbf{b}_{1}$ contains the $\mathrm{BG}$ weights for the first $\mathrm{BG}$; vector $\mathbf{b}_{2}$ contains the BG weights for the second BG; and matrix G contains the genetic correlations between BG traits (Table 2). This equation was also used to calculate the correlation between 1 trait and the whole BG to be able to compare with the NTM. In that case vector $\mathbf{b}_{2}$ contains a 1 for the represented trait and 0 for the other traits. The correlations were calculated with the procedure IML in SAS statistical software (version 9.3, SAS Institute Inc., Cary, NC).

\section{Desired Gains Approach}

The BGOrgPrin was based on the POA defined by the IFOAM (2016). To interpret these principles, a questionnaire was sent out to several farmers, researchers, and experts in the area of organic animal husbandry from May 2016 until October 2016. Participants were given a short introduction to the project and IFOAM's official definition of the 4 POA (IFOAM, 2016) and then asked whether each of the traits in this study was (1) not at all, (2) somewhat, or (3) very much related to each of the 4 POA. The trait beef production was included in the study after the questionnaire had been sent out, but was regarded as similar to milk production in terms of relatedness to the POA. The purpose of the questionnaire was not to get a representative answer, but to get external experts' guidance on how to prioritize traits related to the POA. The number of participants responding that a trait was very much related to a particular principle was used to determine for which traits genetic gain should be maximized for BGOrgPrin. Traits were chosen within each principle if a higher number of participants gave this rating to a trait compared with the other traits. Traits chosen for each principle were then added together to get all traits that needed to have maximized genetic gain for BGOrgPrinc. For BGDis, the aim was to maximize genetic gain for resistance to mastitis, hoof and leg diseases, and other diseases. For BGFeed, the aim was to maximize genetic gain for roughage consumption and feed efficiency. We chose the trait groups diseases and feed efficiency because they resemble key elements of organic dairy production that align with the POA. No genetic decline was accepted in any of the other traits in BGOrgPrin, BGDis, and BGFeed. An optimization program in $\mathrm{R}$ using a grid search was developed to determine BG weights for all traits that matched desired genetic change for the last $3 \mathrm{BG}$. The inputs for this program were genetic correlations, heritability, genomic EBV reliability, and BG weight in BGOrgEc for each trait. A range of relative economic weights was evaluated by the program, such as $1,50,150$, and $200 \%$ of the BG weight in BGOrgEc. A trait can have a target genetic change of 0 if required, and a linear combination 
of traits can be optimized in terms of genetic change. The program gives expected genetic change based on male superiority with a selection intensity of 1 for the full range of relative economic weights evaluated. The BG weights that predicted the genetic change that was closest to the desired genetic change were chosen as BG weights for BGOrgPrin, BGDis, and BGFeed.

\section{Simulation}

Each BG was simulated for $30 \mathrm{yr}$ and replicated 20 times in the stochastic simulation program ADAM (Pedersen et al., 2009), which simulates a population of animals and tracks genetic change in individual traits and the aggregate genotype. A pseudo-genomic setup was used, similar to the method developed by Dekkers (2007). This means that no genetic markers were simulated, but instead 12 genomic traits were used, which were the direct genomic value (DGV) for each of the 12 traits included in this study. These genomic traits were correlated with a corresponding trait, with a correlation equal to the accuracy of DGV for that trait; a more detailed description of the method can be found in Buch et al. (2012). Accuracy of DGV were based on average genomic EBV reliability values for young bulls born in 2014 (Table 3; L. P. Sørensen, SEGES Cattle, Aarhus, Denmark, personal communication, September 8,2016 ). The genetic and environmental (co)variance matrix for the pseudo-genomic simulations, $G$ and R, were computed according to Dekkers (2007) with genetic, phenotypic, and residual correlations between traits, heritabilities, and genetic and phenotypic variances. The $\mathbf{G}$ matrix was not positive-definite, and thus it was bent before being used in the simulation. The output of the simulation was analyzed using $\mathrm{R}$ statistical software. An ANOVA test was performed followed by Fisher's LSD test to find pairwise differences between all BG for genetic change in each of the 12 traits.

\section{Population}

The simulated population was created to reflect the Danish Holstein population. The simulated breeding population consisted of 20,000 cows distributed in 200 herds. These animals were divided into the age classes 1 to $6 \mathrm{yr}$ for cows and 1 to $5 \mathrm{yr}$ for bulls. Every year, the 2,000 best bull calves and the 2,000 best heifer calves were genotyped (ranked based on parent average). Bull calves from reproductive technologies had a different sex class and had priority in this selection step. The 100 best genotyped bulls between 1 to 2 yr old were selected for breeding (ranked based on estimated breed- ing values that include information on the genomic traits). The 200 best genotyped heifers were selected for multiple ovulation embryo transfer and produced 10 progeny each from 5 different sires, with a sex ratio of $50 \%$. The remaining cows produced 1 calf each every year. Unselected animals, bulls above 5 yr old, and females above $6 \mathrm{yr}$ old were culled. In addition, $15 \%$ of all animals were randomly culled before selection decisions were made. Animals were selected based on a total merit index including all 12 traits with different BG weights per BG. The ADAM program was used to simulate true breeding values and phenotypes, and the DMU package (Madsen and Jensen, 2013) was used to predict breeding values. The model used combined all information in 1 step; see Buch et al. (2012) for a more detailed description of this method. To facilitate comparisons between $\mathrm{BG}$, the population structure and breeding scheme were kept the same for all BG, although a population specifically bred for organic production would not include embryo transfer under the current regulations for organic dairy production.

\section{RESULTS}

\section{Questionnaire About Breeding Traits and POA}

In total, 29 participants answered the questionnaire: 3 farmers, 15 international experts and researchers, 5 employees from breeding organizations, and 6 employees from farm advisory groups. Most participants originated from Denmark and Sweden. Table 4 shows the number of participants that rated a trait as very much related to each principle.

Table 4. Number of participants rating each trait ${ }^{1}$ as very much related to each of the principles of organic agriculture defined by the International Federation of Organic Agriculture Movements (IFOAM, $2016 ; \mathrm{n}=29$ participants)

\begin{tabular}{lcccc}
\hline & \multicolumn{4}{c}{ Principle of organic agriculture } \\
\cline { 2 - 5 } Trait & Health & Ecology & Fairness & Care \\
\hline Cow fertility & 16 & 13 & 7 & 13 \\
Heifer fertility & 14 & 12 & 6 & 12 \\
Calving difficulty & 17 & 6 & 13 & 17 \\
Calf mortality & 24 & 10 & 17 & 21 \\
Cow mortality & 24 & 10 & 18 & 20 \\
Hoof and leg diseases & 28 & 9 & 13 & 18 \\
Mastitis & 27 & 9 & 13 & 17 \\
Other diseases & 24 & 6 & 12 & 16 \\
Milk production & 3 & 8 & 9 & 6 \\
Feed efficiency & 4 & 17 & 7 & 8 \\
Roughage consumption & 8 & 19 & 9 & 10 \\
\hline
\end{tabular}

${ }^{1}$ Beef production was not included in the questionnaire but was regarded as similar to milk production in terms of relatedness to the principles of organic agriculture. 
Principle of Health. Most participants rated the traits calf mortality, cow mortality, hoof and leg diseases, mastitis, and other diseases as very much related to this principle. More than half of the participants rated cow fertility, heifer fertility, and calving difficulty as very much related to this principle.

Principle of Ecology. More than half the participants rated the traits feed efficiency and roughage consumption as very much related to this principle.

Principle of Fairness. More than half the participants rated the traits calf mortality and cow mortality as very much related to this principle.

Principle of Care. More than half the participants rated the following traits as very much related to this principle: calving difficulty, calf mortality, cow mortality, hoof and leg diseases, mastitis, and other diseases.

The traits that were rated as very much related to each of these principles by most participants (evaluated per principle) were added together to determine desired gain for BGOrgPrin. The results of the questionnaire indicated that participants regarded the following 8 traits as very much related to the POA: calving difficulty, calf mortality, cow mortality, hoof and leg diseases, mastitis, other diseases, feed efficiency, and roughage consumption. Therefore, for BGOrgPrin, these traits needed to achieve as much favorable genetic change as possible without causing unfavorable genetic change in any of the other traits. The desired genetic changes resulted in the BG weights shown in Table 3.

\section{Differences in Genetic Change Between Scenarios}

Genetic change in genetic standard deviation $\left(\boldsymbol{\sigma}_{\mathrm{a}}\right)$ units per year is shown in Figure 1. According to the ANOVA test, at least 1 of the BG differed from the others in genetic change for all traits. For the traits cow fertility, heifer fertility, calving difficulty, calf mortality, hoof and leg diseases, mastitis, other diseases, and roughage consumption genetic change in $\sigma_{\mathrm{a}}$ units per year was significantly different between at least 5 BG. Genetic change in $\sigma_{\mathrm{a}}$ units per year for BGConvEc, BGOrgEc, and BGFarmPref were similar for all traits, and we found no significant differences between these 3 BG for genetic change in milk production, beef production, and feed efficiency. Milk production and feed efficiency had very high favorable genetic change in BGConvEc, BGOrgEc, and BGFarmPref compared with the other BG, and beef production, cow fertility, and heifer fertility had very high unfavorable genetic change compared with the other BG. All traits achieved favorable genetic change in BGOrgPrin, BGFeed, and BGDis, although genetic change in some traits was very low, such as milk production in BGOrgPrin. Calf mortality, cow mortality, and roughage consumption were the traits with the smallest differences in genetic change in $\sigma_{\mathrm{a}}$ units per year between BG. For milk production and mastitis, the differences in genetic change in $\sigma_{\mathrm{a}}$ units per year between BG were large.

\section{Correlations}

Correlations between BG are shown in Table 5. Correlations between BGConvEc, BGOrgEc, and BGFarmPref were all close to unity. Correlations between all the other BGs were lower than 0.8. Correlations between 1 trait and each BG are shown in Table 6.

\section{DISCUSSION}

\section{Implementation of a Breeding Goal for Organic Dairy Production}

In our study, several different BG were set up for organic dairy production in Denmark. The results revealed that the BG that would be most suitable for organic dairy production depends on different factors. Using economic models to determine BG weights for organic dairy production (BGOrgEc) led to unfavorable genetic changes in cow fertility, heifer fertility, calving difficulty, hoof and leg diseases, mastitis, and beef production in our study. This was partly due to a high BG weight because of the high economic value of milk production, and partly due to unfavorable genetic correlations between milk production and fertility, disease, and beef production traits. Deterioration of the functional traits would be undesirable in most breeding programs. According to the participants in our questionnaire, deterioration of the functional traits is also in conflict with the POA, and an alternative BG may be necessary. The BGOrgPrin, BGDis, or BGFeed options presented in our study are potential alternatives, but it is questionable whether these BG will give enough favorable genetic change in milk production for economically sustainable production. This is particularly important, as Slagboom et al. (2016a,b) showed that organic dairy farmers in Denmark preferred improvements in production traits more than conventional farmers did; however, the survey by Slagboom et al. (2016a,b) did not include assessment of long-term consequences of preferences. If farmers see the consequences for genetic change in functional traits when they put more weight on production traits, they might choose differently, as reported, for example, in a study of Swedish farmers' preferences (Ahlman et al., 2014).

Farmers' preferences are important, but they need to be viewed in the framework of guidelines for organic dairy production. An important factor to consider here is that organic certification companies and legislators 
Table 5. Correlations between breeding goals ${ }^{1}$

\begin{tabular}{lccccc}
\hline Item & BGOrgEc & BGFarmPref & BGOrgPrin & BGDis & BGFeed \\
\hline BGConvEc & 0.998 & 0.997 & 0.278 & 0.190 & 0.617 \\
BGOrgEc & & 0.998 & 0.271 & 0.176 & 0.606 \\
BGFarmPref & & 0.227 & 0.150 & 0.583 \\
BGOrgPrin & & & 0.690 & 0.783 \\
BGDis & & & & 0.367 \\
\hline
\end{tabular}

${ }^{1}$ Breeding goals: BGConvEc $=$ conventional based on economic models; BGOrgEc $=$ organic based on economic models; BGFarmPref = organic based on farmers' preferences; BGOrgPrin = organic based on principles of organic agriculture; BGDis = organic with extra emphasis on disease resistance; BGFeed = organic with extra emphasis on roughage consumption and feed efficiency.

may decide that guidelines for organic farming need to be updated in a way that changes the importance of traits in the BG. A hypothetical example is a stronger restriction on the use of antibiotics in organic production. Such a change would decrease the difference between BGDis and a recalculated BGOrgEC. All BG were run in a scenario that included embryo transfer. In organic dairy production in Denmark, on-farm embryo transfer it is not allowed, but using semen from a bull that is the product of embryo transfer is allowed. Using embryo transfer will increase genetic gain, and if scenarios would not have included embryo transfer overall genetic gain would have been lower, but this would not have influenced the relativity of comparisons.

Breeding goals are set based on a production system in an average organic Danish dairy farm. However,

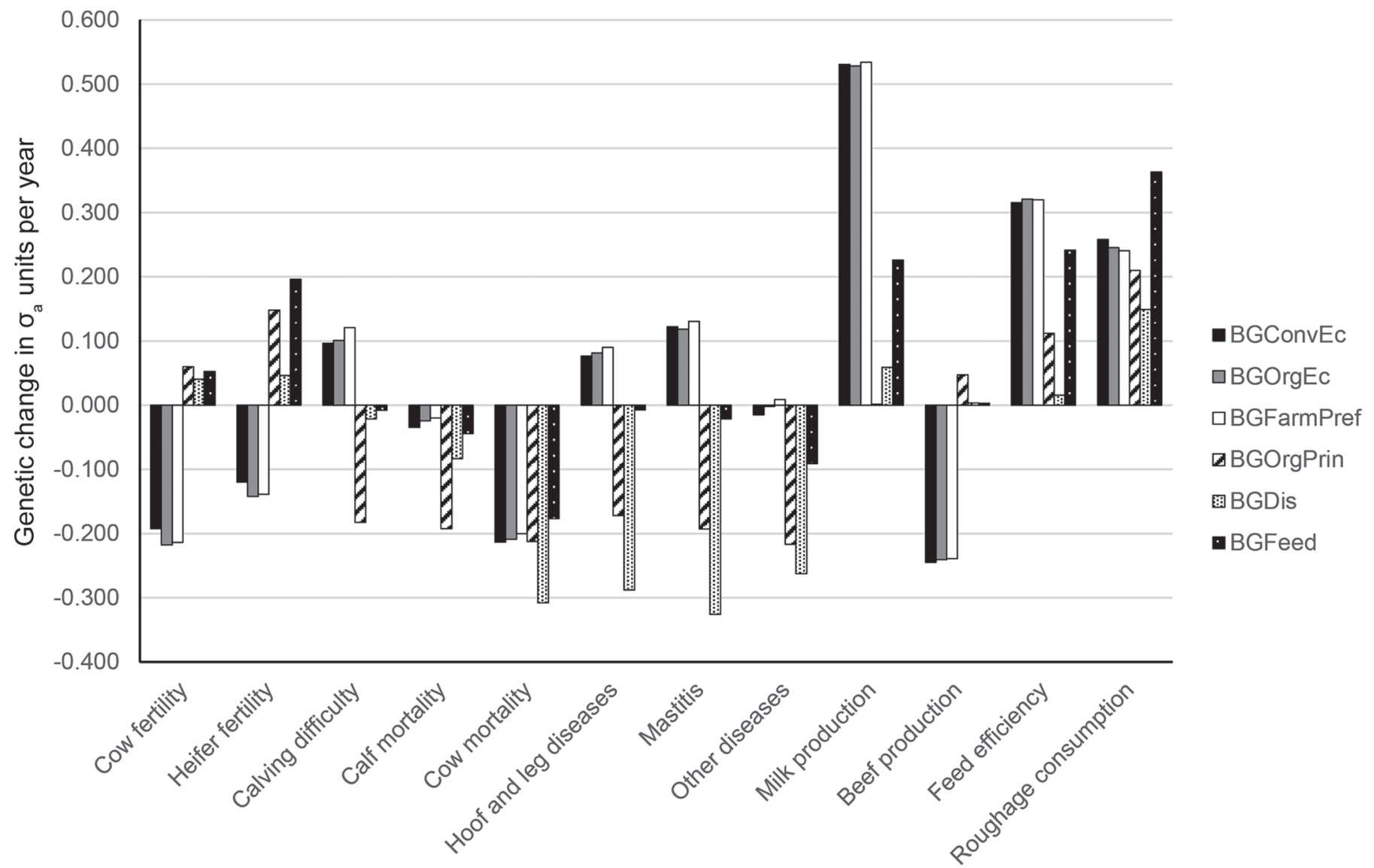

Figure 1. Genetic change in genetic standard deviations $\left(\sigma_{\mathrm{a}}\right)$ units per year for all traits simulated and for each of the 6 breeding goals. BGConvEc $=$ conventional based on economic models; BGOrgEc $=$ organic based on economic models; BGFarmPref $=$ organic based on farmers' preferences; BGOrgPrin = organic based on principles of organic agriculture; BGDis = organic with extra emphasis on disease resistance; BGFeed = organic with extra emphasis on roughage consumption and feed efficiency. 
Table 6. Correlations between each trait and the whole breeding goal for every breeding goal ${ }^{1}$

\begin{tabular}{lrrrrrr}
\hline Trait $^{2}$ & BGConvEc & BGOrgEc & BGFarmPref & BGOrgPrin & BGDis & BGFeed \\
\hline CoF & -0.40 & -0.45 & -0.44 & 0.01 & 0.07 & 0.01 \\
HeF & -0.21 & -0.25 & -0.25 & 0.32 & 0.08 & 0.44 \\
CD & 0.19 & 0.19 & 0.23 & -0.34 & -0.07 & -0.03 \\
CaM & -0.07 & -0.05 & -0.04 & -0.36 & -0.15 & -0.08 \\
CoM & -0.42 & -0.40 & -0.39 & -0.40 & -0.61 & -0.35 \\
HLD & 0.16 & 0.16 & 0.18 & -0.35 & -0.68 & -0.01 \\
MA & 0.23 & 0.23 & 0.25 & -0.34 & -0.64 & -0.02 \\
OD & -0.06 & -0.03 & -0.01 & -0.47 & -0.61 & -0.14 \\
MP & 0.97 & 0.96 & 0.97 & 0.05 & 0.05 & 0.46 \\
BP & -0.49 & -0.47 & -0.47 & 0.05 & -0.01 & 0.01 \\
FE & 0.72 & 0.75 & 0.73 & 0.40 & 0.03 & 0.64 \\
RC & 0.57 & 0.53 & 0.53 & 0.44 & 0.28 & 0.70 \\
\hline
\end{tabular}

${ }^{1}$ Breeding goals: BGConvEc $=$ conventional based on economic models; BGOrgEc $=$ organic based on economic models; BGFarmPref = organic based on farmers' preferences; BGOrgPrin = organic based on principles of organic agriculture; BGDis = organic with extra emphasis on disease resistance; BGFeed = organic with extra emphasis on roughage consumption and feed efficiency.

${ }^{2}$ Traits: cow fertility $(\mathrm{CoF})$, heifer fertility $(\mathrm{HeF})$, calving difficulty $(\mathrm{CD})$, calf mortality (CaM), cow mortality $(\mathrm{CoM})$, hoof and leg diseases (HLD), mastitis (MA), other diseases (OD), milk production (MP), beef production $(\mathrm{BP})$, feed efficiency (FE), and roughage consumption (RC).

great variation exists in characteristics of organic dairy farms in Denmark, such as the amount of roughage in the ration and the incidence of diseases. Therefore, the specific production environment on a farm can determine whether BGDis or BGFeed might be more suitable for that specific farm. In that case, it might be interesting to use customized indices on the farm level instead of implementing a specific BG on the population level. This might help to decrease the genetic lag on farm level and on a trait basis, but genetic trends on population level will not change. When implementing a specific BG for organic dairy production on population level, it is important to consider economics and the POA and to ask farmers and other stakeholders about their opinion of these BG. Implementing a separate BG does have practical consequences, such as increased costs for breeding and a decreased breeding population, which could have consequences on inbreeding.

\section{Similarity Between Breeding Goals}

Using economic models for organic and conventional dairy production resulted in very similar genetic change in BG traits, as also shown in the correlation between BGConvEc and BGOrgEc. Preferences of organic farmers on top of the economic values of BGOrgEc resulted in BGFarmPref, which gave a similar genetic change as in BGConvEc and BGOrgEc and a very high correlation between these $3 \mathrm{BG}$. Thus, economic values and farmers' preferences were so similar in our study that it would not make sense to choose a different BG for organic dairy production based on this. Thus, it would be better for genetic gain to use 1 overall $\mathrm{BG}$ for organic and conventional dairy production. Correlations be- tween BGConvEc and BGOrgPrin, BGDis, or BGFeed were lower than 0.61 , the break-even correlation point estimated before the use of genomic selection (Mulder et al., 2006). A correlation above the break-even point means that total genetic gain will be lower when having 2 breeding lines with 2 different BG, and higher when having 1 breeding line with $1 \mathrm{BG}$. This means that if choosing a $\mathrm{BG}$ for organic dairy production based on BGOrgPrin, BGDis, or BGFeed, and a BG for conventional dairy production based on BGConvEc, the correlation between BG would be so low that it would be better for genetic gain to have 2 separate BG.

\section{Comparison with the Nordic Total Merit index}

The current NTM includes more traits than we have included in our study, and some traits are defined differently; thus, a full comparison is difficult. In Table 6 correlations between 1 trait and the whole BG are given, which indicate similarities and differences between the BG in our study and the NTM. Correlations between the NTM and the subindices of the NTM can be found in Nordic Cattle Genetic Evaluation (2017). The correlation between the NTM and the yield index in the NTM was 0.48, which is much lower than the correlation of milk production and BGConvEc, BGOrgEc, and BGFarmPref. The current NTM has correlations with the yield subindex that are comparable with the correlation between BGFeed and milk production, and correlations with health and mortality traits that are most comparable to BGOrgPrin. Correlations with fertility are higher in the NTM than in any of the BG presented here. The consequence is that realized genetic change in fertility might be higher than the 
change presented for all BG in our study, but realized genetic change is a function of more than just breeding goal decisions. Therefore, a straightforward comparison with what is done in real life in the Nordic countries is not possible.

\section{Setting Up Breeding Goals}

Different methods were used in this study to set BG. Kargo et al. (2015) set up BGConvEc and BGOrgEc using a bio-economic model to derive economic values, as described by Østergaard et al. (2016). Although this is a sound way of calculating economic values, farmers did not know that, for example, the economic value of cow fertility was lower in an organic system compared with a conventional system due to very high costs of raising young stock in organic dairy production. When these economic values were used as input for the farmers' preference survey, resulting in BGFarmPref, it might have created some small bias. One example is that the low economic value of cow fertility resulted in a very high improvement in cow fertility being presented to farmers in the survey (as all improvements presented in the survey were equal to a value of $100 \mathrm{DKr}$ ). This might have contributed to the fact that farmers mostly preferred to improve cow fertility over other traits in that study [see Slagboom et al. (2016a,b) for a more detailed discussion on the survey]. The effect of the way in which economic values were calculated on farmers' preferences, and consequently on the BG weights in BGFarmPref, is not known, but is likely to be small considering that the correlation between BGOrgEc and BGFarmPref was near unity.

We set up 3 BG with a desired gains index. There are many ways to make a desired gains index, and we chose to use input from a small questionnaire to decide on desired gains for BGOrgPrin. The number of participants that completed the questionnaire was low, as the goal of the questionnaire was not to get a quantitative response, but to get input for the desired gains for BGOrgPrin. A lot of overlap existed between responses from different participants, and it appeared that the participants understood the definition of each of the POA based on how they responded. Thus, we believe the questionnaire was a good method to get desired gains for BGOrgPrin.

\section{Parameter Assumptions}

The aim of breeding goal simulations are to predict and compare long-term trends in genetic gain of different breeding goals, not to estimate detailed levels of genetic gain. The results are naturally limited by un- certainties in assumptions such as population structure, differences in trait definitions between studies, and the accuracy of the genetic and phenotypic parameters used as input in the simulation. The aim in the present study was to compare differences in breeding goals for organic dairy production in Denmark. Thus, the input data were based on information and parameter estimations from the current breeding evaluation in Denmark and scientific literature reporting from Danish production systems or production systems similar to the Danish, aiming for the best possible prediction of the true traits and parameter estimates.

A BG might have a different effect in different production systems if genetic means and standard deviations are not the same; however, in the Nordic countries, genetic differences between organic and conventional dairy production are small. For example, Sundberg et al. (2009) found differences in means of traits for organic and conventional dairy production in Sweden, but the standard deviations were comparable, only the standard deviation of yield was lower in organic production. Therefore, the consequence of assuming equal standard deviations of traits in this study will have a minimal effect.

\section{CONCLUSIONS}

This study compared BG for organic dairy production, which were set using various methods. Breeding goals based on economic models or on farmers' preferences do not align with the principles of organic agriculture, and thus an alternative base for a BG was set up in this study. The BG that was created based on the principles of organic agriculture could be used as a specific index for organic dairy farming in Denmark, but this index was economically not very sustainable. Hence, an intermediate breeding goal could be developed by breeding companies to address both economics and the principles of organic agriculture.

\section{ACKNOWLEDGMENTS}

This study was part of the SOBcows project work package 1 and the Organic Dairy Health project work package 3. The project SOBcows is part of the Organic RDD 2 program, which is coordinated by the International Centre for Research in Organic Food Systems (ICROFS, Tjele, Demark). It has received grants from the Green Growth and Development program (GUDP) under the Danish Ministry of Food, Agriculture and Fisheries (Copenhagen, Denmark). The FP7 ERA-Net CORE Organic Plus project Organic Dairy Health was supported by funds from the Swedish research council 
for sustainable development (Formas, Stockholm, Sweden) and the Danish Agricultural Agency, Ministry of Environment and Food of Denmark (Copenhagen).

\section{REFERENCES}

Ahlman, T., M. Ljung, L. Rydhmer, H. Röcklinsberg, E. Strandberg, and A. Wallenbeck. 2014. Differences in preferences for breeding traits between organic and conventional dairy producers in Sweden. Livest. Sci. 162:5-14. https://doi.org/10.1016/j.livsci.2013.12 .014 .

Bijma, P., J. Jensen, and P. Madsen. 1998. Genetic and phenotypic parameters of lifetime and stayability traits in Danish dairy breeds. Acta Agric. Scand. A Anim. Sci. 48:155-164. https://doi.org/10 .1080/09064709809362415.

Buch, L. H., and E. Norberg. 2008. Genetic analysis of protein yield, udder health, and female fertility in first-parity Danish Holstein cows. Acta Agric. Scand. A Anim. Sci. 58:5-9. https://doi.org/10 $.1080 / 09064700802079136$.

Buch, L. H., A. C. Sørensen, J. Lassen, P. Berg, L. G. Christensen, and M. K. Sørensen. 2009. Factors affecting the exchange of genetic material between Nordic and US Holstein populations. J. Dairy Sci. 92:4023-4034. https://doi.org/10.3168/jds.2008-1541.

Buch, L. H., M. K. Sørensen, P. Berg, L. D. Pedersen, and A. C. Sørensen. 2012. Genomic selection strategies in dairy cattle: Strong positive interaction between use of genotypic information and intensive use of young bulls on genetic gain. J. Anim. Breed. Genet. 129:138-151. https://doi.org/10.1111/j.1439-0388.2011.00947.x.

Dekkers, J. C. M. 2007. Prediction of response to marker assisted and genomic selection using selection index theory. J. Anim. Breed. Genet. 124:331-341. https://doi.org/10.1111/j.1439-0388.2007 .00701.x.

Dematawewa, C. M. B., and P. J. Berger. 1998. Genetic and phenotypic parameters for 305-day yield, fertility, and survival in Holsteins. J. Dairy Sci. 81:2700-2709. https://doi.org/10.3168/jds .S0022-0302(98)75827-8.

Eaglen, S. A. E., M. P. Coffey, J. A. Woolliams, and E. Wall. 2013. Direct and maternal genetic relationships between calving ease, gestation length, milk production, fertility, type, and lifespan of Holstein-Friesian primiparous cows. J. Dairy Sci. 96:4015-4025. https://doi.org/10.3168/jds.2012-6229.

Fuerst-Waltl, B., and M. K. Sørensen. 2010. Genetic analysis of calf and heifer losses in Danish Holstein. J. Dairy Sci. 93:5436-5442. https://doi.org/10.3168/jds.2010-3227.

Hansen, M., M. S. Lund, M. K. Sørensen, and L. G. Christensen. 2002. Genetic parameters of dairy character, protein yield, clinical mastitis, and other diseases in the Danish Holstein cattle. J. Dairy Sci. 85:445-452. https://doi.org/10.3168/jds.S0022-0302(02)74093-9.

Heise, J., Z. Liu, K. F. Stock, S. Rensing, F. Reinhardt, and H. Simianer. 2016. The genetic structure of longevity in dairy cows. J. Dairy Sci. 99:1253-1265. https://doi.org/10.3168/jds.2015-10163.

IFOAM. 2016. Principles of Organic Agriculture. Accessed Jan. 16, 2017. http://www.ifoam.bio/en/organic-landmarks/principles -organic-agriculture.

Interbull. 2008. National Genetic Evaluation Form Calving traits. Accessed Oct. 4, 2016. https://wiki.interbull.org/public/Nat_GE _Forms?action $=$ AttachFile\&do $=$ get\&target $=$ DFSHOLRDCca.rtf.

Interbull. 2010. National Genetic Evaluation Form Udder health. Accessed Oct. 4, 2016. https://wiki.interbull.org/public/Nat_GE _Forms?action=AttachFile\&do=get\&target=DFSHOLuh.rtf.

Interbull. 2012. National Genetic Evaluation Form Production traits. Accessed Oct. 4, 2016. https://wiki.interbull.org/public/Nat_GE _Forms?action $=$ AttachFile\&do=get\&target $=$ DFSHOLpro.doc.

Interbull. 2015. National Genetic Evaluation Form Fertility. Accessed Oct. 4, 2016. https://wiki.interbull.org/public/Nat_GE_Forms ?action $=$ AttachFile\&do=get\&target $=$ DFSHOLff.rtf.

Kadarmideen, H. N., R. Thompson, and G. Simm. 2000. Linear and threshold model genetic parameters for disease, fertility and milk production in dairy cattle. Anim. Sci. 71:411-419. https://doi.org/ $10.1017 /$ S1357729800055338.

Kargo, M., J. F. Ettema, L. Hjortø, J. Pedersen, and S. Østergaard. 2015. Derivation of economic values for breeding goal traits in conventional and organic dairy production. Pages 403-403 in Book of Abstracts of the 66th Annual Meeting of the European Association for Animal Production. Wageningen Academic Publishers, Wageningen, the Netherlands.

Laursen, M. V., D. Boelling, and T. Mark. 2009. Genetic parameters for claw and leg health, foot and leg conformation, and locomotion in Danish Holsteins. J. Dairy Sci. 92:1770-1777. https://doi.org/ $10.3168 /$ jds.2008-1388.

Li, B., W. F. Fikse, J. Lassen, M. H. Lidauer, P. Løvendahl, P. Mäntysaari, and B. Berglund. 2016. Genetic parameters for dry matter intake in primiparous Holstein, Nordic Red, and Jersey cows in the first half of lactation. J. Dairy Sci. 99:7232-7239. https://doi.org/ 10.3168/jds.2015-10669.

Madsen, P., and J. Jensen. 2013. A User's Guide to DMU. Version 6, release 5.2. Aarhus Univ., Foulum, Denmark.

Miglior, F., B. L. Muir, and B. J. Van Doormaal. 2005. Selection indices in Holstein cattle of various countries. J. Dairy Sci. 88:12551263. https://doi.org/10.3168/jds.S0022-0302(05)72792-2.

Mulder, H. A., R. F. Veerkamp, B. J. Ducro, J. A. M. Van Arendonk, and P. Bijma. 2006. Optimization of dairy cattle breeding programs for different environments with genotype by environment interaction. J. Dairy Sci. 89:1740-1752. https://doi.org/10.3168/ jds.S0022-0302(06)72242-1.

Nordic Cattle Genetic Evaluation. 2017. NAV Routine Genetic Evaluation of Dairy Cattle - Data and Genetic Models. Accessed Mar. 22, 2018. http://www.nordicebv.info/wp-content/uploads/2018/ 03/NAV-routine-genetic-evaluation-032018.pdf.

Oltenacu, P. A., A. Frick, and B. Lindhe. 1991. Relationship of fertility to milk yield in Swedish cattle. J. Dairy Sci. 74:264-268. https:// doi.org/10.3168/jds.S0022-0302(91)78169-1.

Østergaard, S., J. F. Ettema, L. Hjortø, J. Pedersen, J. Lassen, and M. Kargo. 2016. Avoiding double counting when deriving economic values through stochastic dairy herd simulation. Livest. Sci. 187:114-124. https://doi.org/10.1016/j.livsci.2016.03.004.

Pedersen, J., J. Pösö, J.-Å. Eriksson, U. S. Nielsen, and G. P. Aamand. 2015. Young Stock Survival Index Inclusion in NTM. Nordic Cattle Genetic Evaluation (NAV), Aarhus, Denmark.

Pedersen, L. D., A. C. Sørensen, M. Henryon, S. Ansari-Mahyari, and P. Berg. 2009. ADAM: A computer program to simulate selective breeding schemes for animals. Livest. Sci. 121:343-344. https://doi .org/10.1016/j.livsci.2008.06.028.

Slagboom, M., M. Kargo, D. Edwards, A. C. Sørensen, J. R. Thomasen, and L. Hjortø. 2016a. Organic dairy farmers put more emphasis on production traits than conventional farmers. J. Dairy Sci. 99:9845-9856. https://doi.org/10.3168/jds.2016-11346.

Slagboom, M., M. Kargo, D. Edwards, A. C. Sørensen, J. R. Thomasen, and L. Hjortø. 2016b. Herd characteristics influence farmers preferences for trait improvements in Danish Red and Danish Jersey cows. Acta Agric. Scand. A Anim. Sci. 66. https://doi.org/10 $.1080 / 09064702.2016 .1277550$.

Søndergaard, E., M. K. Sørensen, I. L. Mao, and J. Jensen. 2002. Genetic parameters of production, feed intake, body weight, body composition, and udder health in lactating dairy cows. Livest. Prod. Sci. 77:23-34. https://doi.org/10.1016/S0301-6226(02)00023 -4 .

Sørensen, M.K. 1999. Stokastisk simulering af avlsplaner for malkekvæg. Doctoral dissertation, Den Kongelige Veterinær- og Landbohøjskole, Institut for Husdyrbrug og Husdyrsundhed, Frederiksberg C, Denmark.

Spurlock, D. M., J. C. M. Dekkers, R. Fernando, D. A. Koltes, and A. Wolc. 2012. Genetic parameters for energy balance, feed efficiency, and related traits in Holstein cattle. J. Dairy Sci. 95:5393-5402. https://doi.org/10.3168/jds.2012-5407.

Sundberg, T., B. Berglund, L. Rydhmer, and E. Strandberg. 2009. Fertility, somatic cell count and milk production in Swedish organic 
and conventional dairy herds. Livest. Sci. 126:176-182. https://doi .org/10.1016/j.livsci.2009.06.022.

Team Avlsværdivurdering. 2014. Arsstatistik Avl. 2013/14. SEGES Cattle, Aarhus, Denmark.

Team Avlsværdivurdering. 2015. Arsstatistik Avl. 2014/15. SEGES Cattle, Aarhus, Denmark.

The Council of the European Union. 2008. Commission Regulation (EC) No 889/2008. IFOAM EU Group, Brussels, Belgium. https: //www.ifoam-eu.org/sites/default/files/page/files/ifoameu_reg _regulation_dossier_201204_en.pdf.

Vallimont, J. E., C. D. Dechow, J. M. Daubert, M. W. Dekleva, J. W. Blum, C. M. Barlieb, W. Liu, G. A. Varga, A. J. Heinrichs, and C. R. Baumrucker. 2011. Short communication: Heritability of gross feed efficiency and associations with yield, intake, residual intake, body weight, and body condition score in 11 commercial Pennsylvania tie stalls. J. Dairy Sci. 94:2108-2113. https://doi.org/10 $.3168 /$ jds.2010-3888.
Vallimont, J. E., C. D. Dechow, J. M. Daubert, M. W. Dekleva, J. W. Blum, W. Liu, G. A. Varga, A. J. Heinrichs, and C. R. Baumrucker. 2013. Feed utilization and its associations with fertility and productive life in 11 commercial Pennsylvania tie-stall herds. J. Dairy Sci. 96:1251-1254. https://doi.org/10.3168/jds.2012-5712.

Van Arendonk, J. A. M., G. J. Nieuwhof, H. Vos, and S. Korver. 1991 Genetic aspects of feed intake and efficiency in lactating dairy heifers. Livest. Prod. Sci. 29:263-275. https://doi.org/10.1016/0301 -6226(91)90103-W

VanRaden, P. M., A. H. Sanders, M. E. Tooker, R. H. Miller, H. D. Norman, M. T. Kuhn, and G. R. Wiggans. 2004. Development of a National Genetic Evaluation for Cow Fertility. J. Dairy Sci. 87:2285-2292. https://doi.org/10.3168/jds.S0022-0302(04)70049 $-1$.

Weller, J. I., and E. Ezra. 2008. Genetic analysis of the growth rate of Israeli Holstein calves. Animal 2:1717-1723. https://doi.org/10 $.1017 /$ S1751731108003042. 